\title{
Measurement of hydraulic fracture growth in a naturally fractured orebody for application to preconditioning
}

\author{
R.G. Jeffrey CSIRO Earth Science and Resource Engineering, Australia
}

A. van As Rio Tinto Copper Projects, Australia

X. Zhang CSIRO Earth Science and Resource Engineering, Australia

A.P. Bunger CSIRO Earth Science and Resource Engineering, Australia

Z.R. Chen CSIRO Earth Science and Resource Engineering, Australia

\begin{abstract}
Hydraulic fracturing is applied for the preconditioning of orebodies prior to cave mining. A major project at Northparkes Mines was carried out in 2006 to investigate hydraulic fracture interaction with shear zones in the E48 orebody. The fracture growth was remotely monitored by tiltmeter and microseismic arrays. The mined fractures were then physically mapped and their geometry was compared to that inferred from the remote monitoring. The fractures were found to be subhorizontal, which was consistent with the tiltmeter and in situ stress data. Shear zones, natural fractures, and veins were crossed by the hydraulic fractures, sometimes producing an offset or step in the fracture path at the crossing site. One hydraulic fracture terminated at a shear zone in close proximity to a lithological contact that may be a stress change boundary. Numerical modelling of hydraulic fracture growth with offsets reveals that such fractures require a higher pressure to propagate and grow more slowly than a straight fracture. Results from numerical modelling indicated that the E48 caveability would prove problematic. The E48 orebody was, therefore, preconditioned using hydraulic fracturing and the footprint of the cave was enlarged.
\end{abstract}

\section{Introduction}

Hydraulic fracturing is being applied to precondition orebodies for block and panel caving operations in Australia and Chile. In Australia, Northparkes recently undertook a study of hydraulic fracture growth behaviour in their E48 orebody to collect information about fracture growth in competent fractured rock masses containing major shear zones. This data was then used in the design of a full, mine-scale preconditioning program.

The study used a range of monitoring methods to collect information about hydraulic fracture growth in the orebody. Remote monitoring instrumentation used in this project consisted of a microseismic array, two tiltmeter arrays, and two piezometers installed into boreholes near the hydraulic fracturing site. This remote monitoring data was evaluated and compared with results from physical mapping of the fracture geometries that was collected as a tunnel was driven through the zone containing the fractures. In particular, the mapping focused on documenting the fracture orientation for comparison with the orientation inferred from the remote monitoring data. In addition, the interaction of the hydraulic fractures with one another and with pre-existing natural fractures, veins and major shear zones was studied in detail. The microseismic monitoring array consisted of ten triaxial accelerometers, and the surface tiltmeter array consisted of eleven instruments installed in $8 \mathrm{~m}$ deep vertical holes. The in situ stresses were known from prior overcore stress measurements, in a nearby orebody, and subsequent measurements were conducted in E48 after the mine through was complete.

\section{Preconditioning}

Methods to introduce new fractures to weaken the rock mass and enhance its caveability are needed, particularly if less fractured, stronger orebodies, some with smaller footprints, are to be reliably mined by 
block caving methods. Preconditioning should therefore result in an orebody that will cave continuously and more uniformly with the formation of smaller fragment size (Brown, 2003).

Hydraulic fracturing was introduced, as both a cave inducement and preconditioning tool, in 1997 when it was first used at Northparkes Mines (van As and Jeffrey, 2000). Since then, hydraulic fracturing has been applied to the preconditioning of orebodies at Northparkes Mine (van As et al., 2004) and Ridgeway Gold Mine in Australia, and at Codelco's Salvador, Andina, and El Teniente mines in Chile (Chacon et al., 2004).

\subsection{Fracture initiation from the borehole}

Hydraulic fractures are initiated from a borehole and can be extended to more than $50 \mathrm{~m}$ radius, which means only a relatively few boreholes are needed to precondition a large orebody. The hydraulic fractures are created by isolating a short section of the borehole, typically by using open-hole inflatable packers. The fracture fluid, which can range from water to a thick water based gel fluid, is then pumped into the isolated section, increasing the fluid pressure acting on the borehole wall. The pressure induces tensile tangential stress at the borehole wall and these stresses quickly reach a level that is sufficient to either initiate a new fracture or open a natural fracture. Natural fractures at any orientation in the pressurised section may be opened before a new fracture is created, depending on the stress acting on the borehole, the orientation of the natural fracture, and the strength of the unfractured rock. Hydraulic fractures that initiate with an orientation that is not compatible with growth in the far field in situ stresses will reorient to grow in the plane of $\sigma_{1}$ and $\sigma_{2}$ so they open against $\sigma_{3}$. Figure 1 shows two cases for fracture initiation from a borehole that is drilled parallel to $\sigma_{3}$. Figure 1(a) shows a case of transverse fracture initiation from transverse natural fractures or slots cut in the borehole wall. In this case the hydraulic fractures initiate with the preferred orientation and continue to extend in that same plane. Figure 1(b) shows the case where the fracture initiates along the axis of the borehole by a process of the rock failing in tension. The fracture reorients as it extends away from the borehole induced stress field to align with the far-field stress directions. Such reorientation typically results in en echelon and stepped fractures in curving sections of the fracture which, in turn, leads to higher pressures as the fluid is forced through this tortuous flow path.



a)



Figure 1 Transverse fracture initiation from a borehole aligned with $\sigma_{3}$ direction. Fractures initiate from circumferential slots (a) and by tensile failure along axis of borehole (b)

The pressure required to initiate a fracture at the borehole is typically the highest pressure reached during a fracture treatment. The stress at the borehole wall that must be reached to initiate a fracture is called the breakdown (or initiation) pressure, $P_{b}$. Assuming the hole is aligned along the direction of the minimum principal stress direction, the breakdown pressure for an axial fracture can be estimated using (Jaeger and Cook, 1976):

$$
P_{b}=3 \sigma_{2}-\sigma_{1}+T-p
$$


In Equation (1) (which applies to the condition shown in Figure 1(b)), $\sigma_{2}$ is the minimum principal in plane stress, and $\sigma_{1}$ is the maximum principal in plane stress, with both stresses acting in the plane perpendicular to the borehole axis. The tensile strength of the rock is denoted by $T$ and $p$ is the pore pressure in the rock. Equation (1) gives the pressure required to initiate an axial fracture at the borehole wall, without considering poroelastic effects. The breakdown pressure for a borehole in a homogeneous, isotropic poroelastic rock is given by Equation (2) (Detournay and Cheng, 1993):

$$
P_{b}=\frac{3 \sigma_{2}-\sigma_{1}+T-2 \eta p}{2(1-\eta)}
$$

where $\eta$ is a poroelastic parameter that can range from 0 to 0.5 and typically has a value of about $0.25-0.35$ for sandstone and 0.08-0.16 for granite (Detournay and Cheng, 1993). Equation (2) is valid for slow pressurisation of the borehole, where the fluid in the hole is the same as the reservoir fluid and has time to invade into the surrounding rock. Comparing Equations (1) and (2), it can be seen that the poroelastic effect reduces the breakdown pressure. Once the axial fracture initiates, it will rotate to become aligned and to grow in the plane of $\sigma_{2}$ and $\sigma_{1}$, as shown in Figure 1(b). Note that the fracture leading edge aligned along the $\sigma_{1}$ direction will also twist, as indicated by the series of short line segments, as it grows into the far-field stress conditions. This twisting or turning will be associated with segmentation of the fracture plane. The fracture path from the wellbore to the far-field will eventually be complex, with a multiple subparallel and en echelon stepped fracture geometry forming. Forcing fluid through such a path requires higher pressure than when the fracture is planar as shown in Figure 1(a) and the final position of the main fracture plane along borehole axis is not controlled by the location of the straddle packers.

If a natural fracture or circumferential flaw or slot exists in the borehole, the hydraulic fracture can initiate with a transverse orientation at this location. Indeed, it is advantageous to align the borehole to run approximately parallel to the minimum principal stress direction. If circumferential slots are then cut along the borehole, the fracture initiation points (and initial fracture spacing) are defined by the slots and the fracture extends from the slot with an orientation very near the one preferred and as dictated by the far-field stress conditions, as shown in Figure 1(a). Equation (3) gives the pressure needed to extend such a circumferential slot, assuming the slot has a sharp crack-like tip.

Assuming an HQ size borehole (96 mm diameter) that has a notch of depth $D$ cut into it, the pressure needed to initiate a fracture from this notch can be estimated from (Lhomme et al., 2005):

$$
P_{\text {critical }}=\frac{K_{I c}}{2 f(c)} \sqrt{\frac{\pi}{R}}+\sigma_{3}
$$

where $K_{I c}$ is the fracture toughness of the rock, and $R$ the sum of the borehole radius and the depth of the notch, $D$. The parameter $c$ is equal to $D / R$ and Equation (4) gives $f(c)$ for a uniformly pressurised notch case:

$$
f(c)=\frac{\sqrt{c(c+2)}}{c+1}
$$

According to Equation (3), notches 40-50 mm deep in the wall of an HQ borehole will reduce the initiation pressure considerably (a 50\% reduction compared to that predicted by Equation (1)) and the fractures will be spaced evenly along the borehole as intended by the preconditioning design.

\section{$3 \quad$ Hydraulic fracturing}

The hydraulic fracture is extended into the rock mass by the injected high-pressure fracturing fluid. The fluid enters, pressurises and opens the fracture, causing it to grow further into the rock mass. As the fracture grows, it creates new rock surface area and connects smaller natural fractures together into a single larger fracture plane.

Because the fluid in the hydraulic fracture is at a high pressure compared to the pore pressure in the rock, some portion of it will leak off into the surrounding rock. The ratio of the volume contained in the hydraulic fracture to the total injected volume, at any time, is called the efficiency. The efficiency decreases with time throughout the injection as the fracture surface area increases, and hydraulic fractures propagated using water 
will typically have efficiencies that are less than $50 \%$ by the end of the injection process. If a more viscous gel fluid is used, then less fluid is lost into the surrounding rock at any point in time and the fracture process is more efficient. Experience has shown that in typical deep orebodies, injection of water at $300-400 \mathrm{~L} / \mathrm{min}$ is able to create a fracture with a radius of $50 \mathrm{~m}$ or more. However, the exact fracture growth rate and ultimate size will depend on local conditions.

Hydraulic fracture design models are available to calculate fracture length, opening and fluid loss with time for any given rock mass, fluid, and injection rate parameters. However, even the best model requires some calibration since the hydraulic fracture growth through naturally fractured rock is not yet completely understood and the available models are not able to directly match the treating pressure and growth measured without adjustment to the input data.

The fluid lost from the hydraulic fracture pressurises the surrounding rock. This increase in pore pressure will cause both dilation and slip or shear to occur on natural fractures in the rock mass. The dilation of the natural fracture system results in an increase in the permeability of the rock mass especially near the hydraulic fracture, which, in turn increases the rate of fluid loss into the rock from the hydraulic fracture. Thus, hydraulic fractures growing in a rock mass with an initially low permeability may have efficiencies of $50 \%$ when a low-viscosity fluid such as water is used. The shear slip of natural fractures around the hydraulic fracture will produce microseismic events, which can be mapped to obtain information about the orientation and size of the hydraulic fracture. The shear deformation also imparts damage to the rock mass, weakening it to some degree. In addition, the in situ deviatoric stress is reduced as a result of the shear events reflected in the microseismic activity and by introducing fractures and damaging the rock, zones of stronger and/or stiffer rock are weakened and softened. The risk of rock bursting is, therefore, also reduced in the region treated by hydraulic fracturing.

The mechanical opening of the hydraulic fracture, which is associated with an internal excess pressure of 2-5 MPa, will impose a stress change in the rock mass that extends out to approximately one fracture radius from the plane of the fracture (Soliman et al., 2008; Mills and Jeffrey, 2004). The stress change at points along the sides of the fracture is compressive while ahead of the fracture's leading edge a smaller tensilegoing stress change occurs (Mills and Jeffrey, 2004). During a preconditioning operation, a unit volume of the rock mass will be subject to perhaps 20-30 cycles of this stress change. This loading is expected to impart some damage to the rock mass and may result in additional shear deformation along natural fractures. Figure 2 shows the stress change around a circular pressurised fracture.



Figure 2 Tensile and compressive stress change around a uniformly pressurised radial fracture 
A third process that contributes damage to the rock mass is chemomechanical weakening. Exposure of a dry sedimentary rock to water is known to result in a reduction of compressive and tensile strength that can range from $10 \%$ to over 50\% (Varley and Whyatt, 2008; Ray et al., 2006). Saturating a rock with water of different composition to the connate water can also result in a weakening (or, in some cases, strengthening) effect. Therefore, the chemistry of the fluid injected during hydraulic fracturing should be designed to enhance the overall rock mass weakening effect.

\section{$4 \quad$ Project description}

The research project carried out during development of the E48 orebody at Northparkes was designed to determine if the hydraulic fractures would grow through subvertical shear zones present in the orebody. Additional details of this project and results from it are contained in Jeffrey et al. (2009b). The hydraulic fractures were placed ahead of tunnel ED4 at the extraction level, approximately in the centre of the orebody. Tunnel ED4 was driven to the edge of the orebody (see Figures 3 and 4) and an HQ-size geotechnical investigation borehole was cored along its planned extension. The hydraulic fractures were placed from this horizontal borehole at distances between $70 \mathrm{~m}$ and $132 \mathrm{~m}$ from hole collar. Coloured plastic particles were added to the fracturing fluid to clearly mark the fractures during, and after, mining as ED4 was extended through them.

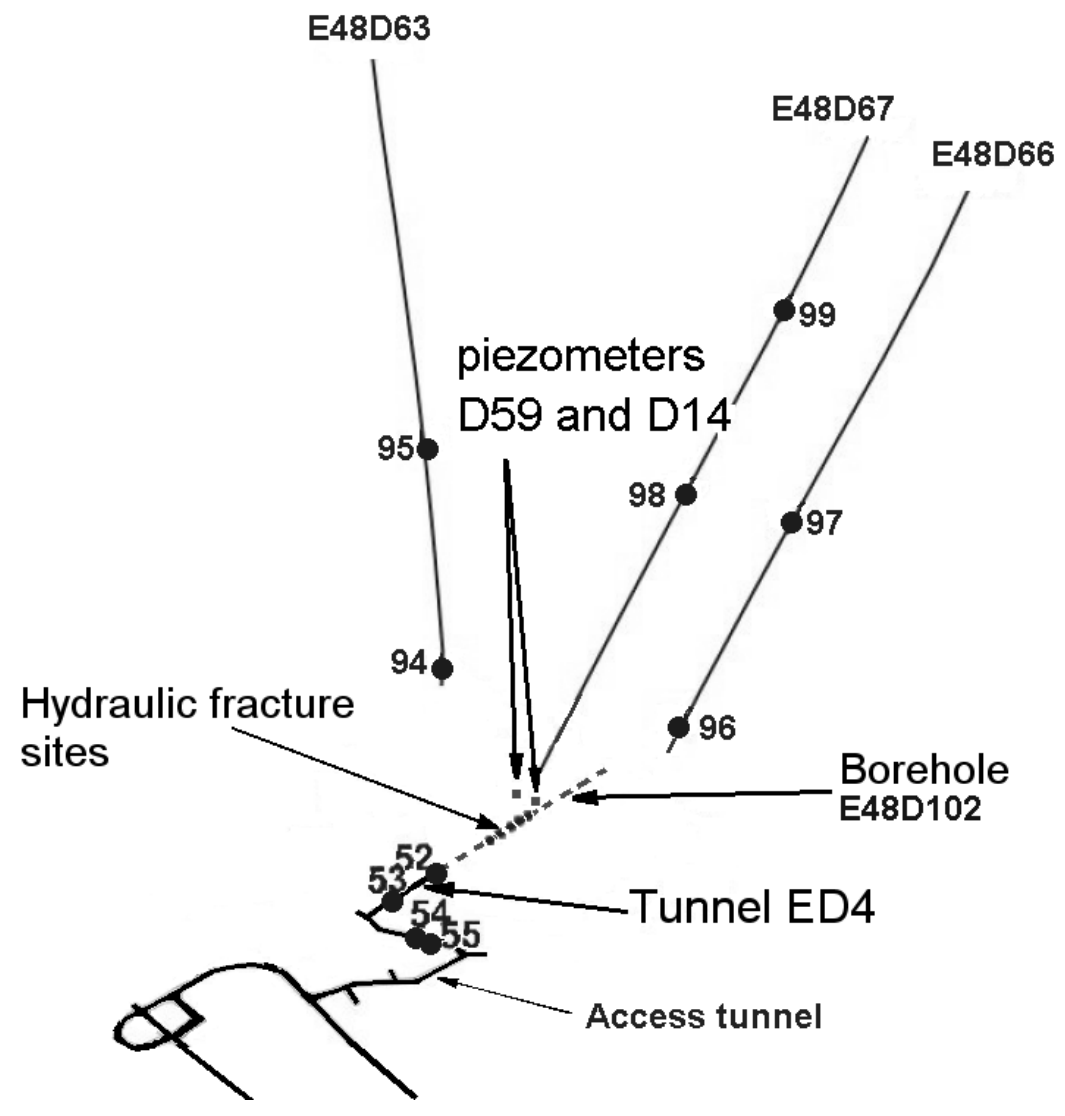

Figure 3 The locations of the triaxial microseismic accelerometers are indicated by the numbered dots. The access tunnel and the path of tunnel ED4 along borehole E48D102 are shown 


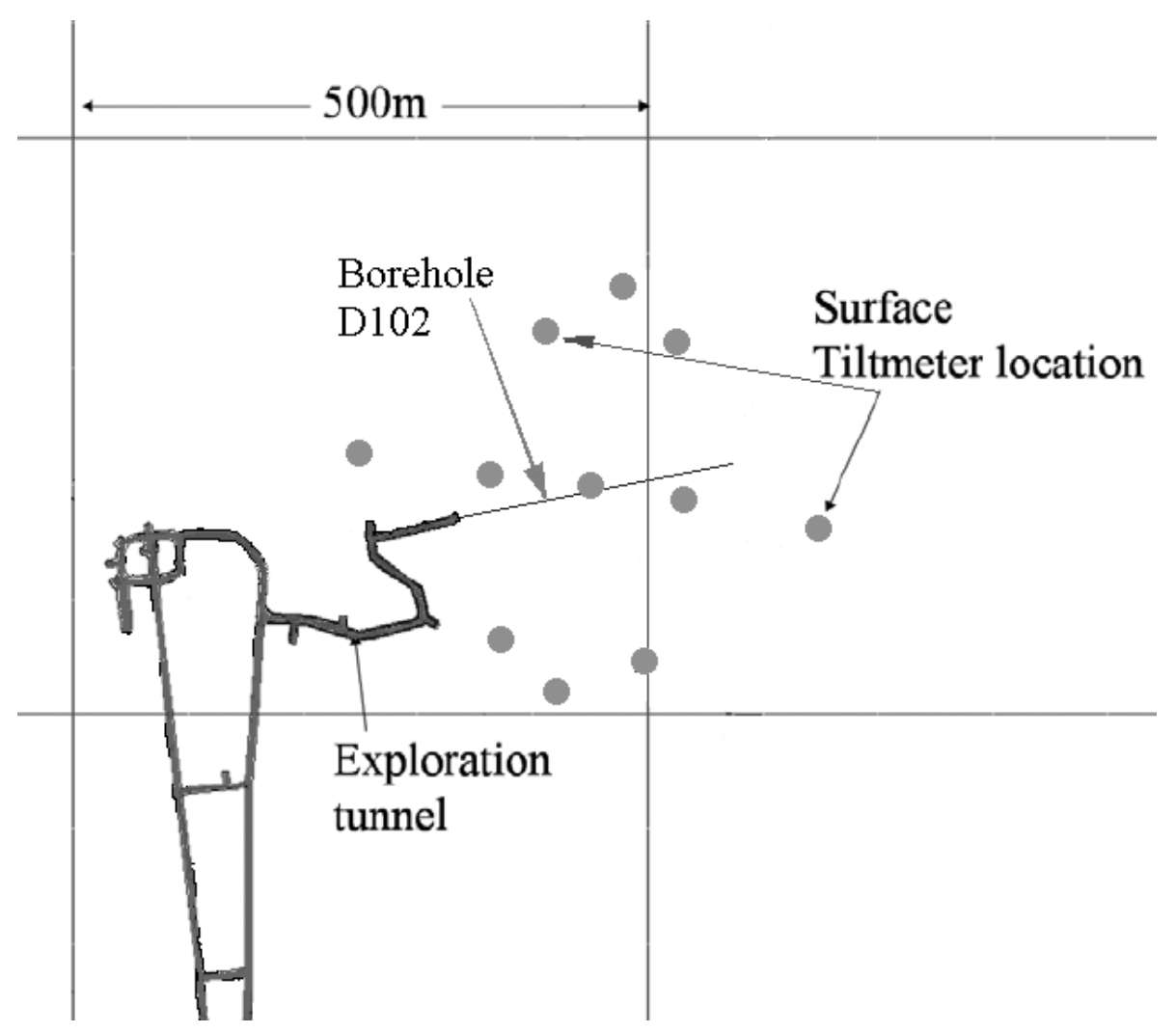

Figure 4 Surface tiltmeter array (circles) overlain on the underground tunnel system

A microseismic array consisting of 10 triaxial accelerometers and an 11 instrument surface tiltmeter array were installed on the site. Piezometers were installed into two existing exploration boreholes that passed near the site on the 9700 level. The injection rate, pressure and packer pressure were recorded throughout each fracture treatment. Analysis of the microseismic and tilt data provides information about fracture size, shape, orientation and volume. The piezometers were monitored to detect any hydraulic fracture growth through these boreholes. The microseismic array and the underground location of the two piezometers are shown in Figure 3 while the surface tiltmeter array is shown in Figure 4. An underground tiltmeter array was also deployed, but the signal recorded by these instruments was strongly affected by the induced deformation of the tunnel they were installed from and the data could, therefore, not be used. In general, to avoid a tunnel effect, underground tiltmeters need to be installed into vertical holes at a depth of more than 1.5 tunnel diameters below the tunnel.

\section{Characterisation}

Figure 5 contains a vertical section through the orebody showing the geology and the major shear zones mapped from surface core holes. The orebody comprises a monzonite porphyry intruded into a sequence of volcanic sediments. Quartz and calcite filled veins are common and the rock mass is naturally fractured with a mean fracture spacing of six fractures per metre. 




\section{Figure 5 Vertical section through orebody showing geology}

Table 1 summarises the rock and rock mass strength and elastic properties for the E48 site (van As, 2004). The stresses were measured by overcoring and Table 2 contains a summary of the two measurements made from ED4 after the fractures were mined (Mills, 2007).

Table 1 Rock properties from core tests

\begin{tabular}{llllll}
\hline Lithology & $\begin{array}{l}\text { UCS Core } \\
(\mathbf{M P a})\end{array}$ & $\begin{array}{l}\mathbf{E}^{(\mathbf{1})} \\
(\mathbf{G P a})\end{array}$ & $\begin{array}{l}\text { Poisson's } \\
\text { Ratio }\end{array}$ & $\begin{array}{l}\text { Bulk Density } \\
(\mathbf{g} / \mathbf{c c})\end{array}$ & $\begin{array}{l}\text { UCS Rock Mass } \\
(\mathbf{M P a})\end{array}$ \\
\hline FQS & 95.7 & - & - & 2.72 & 21 \\
POR & 136.5 & 51.0 & 0.17 & 2.66 & 40 \\
VCCL & 93.8 & 50.8 & 0.11 & 2.75 & 27 \\
VBR & & & & & \\
VSS & 127.4 & 60.0 & 0.22 & 2.78 & 39 \\
\hline
\end{tabular}

UCS - unconfined compressive strength

(1) Tangent Young's modulus; FQS - Fault Quartz Sericite alteration assemblage; POR - Monzonite Porphyry; VCCL -Volcaniclastic; VBR - Volcanic breccia; VSS - Volcanic sandstone 
Table 2 Overcore stress measurement results at E48

\begin{tabular}{|c|c|c|c|c|c|c|c|c|c|}
\hline \multirow[t]{2}{*}{ Measurement } & \multicolumn{3}{|l|}{$\sigma_{1}$} & \multicolumn{3}{|l|}{$\sigma_{2}$} & \multicolumn{3}{|l|}{$\sigma_{3}$} \\
\hline & $\begin{array}{l}\text { Mag. } \\
\text { (MPa) }\end{array}$ & $\begin{array}{l}\text { Dip } \\
\text { (deg) }\end{array}$ & $\begin{array}{l}\text { Azimuth } \\
\text { (deg) }\end{array}$ & $\begin{array}{l}\text { Mag. } \\
\text { (MPa) }\end{array}$ & $\begin{array}{l}\text { Dip } \\
\text { (deg) }\end{array}$ & $\begin{array}{l}\text { Azimuth } \\
\text { (deg) }\end{array}$ & $\begin{array}{l}\text { Mag. } \\
\text { (MPa) }\end{array}$ & $\begin{array}{l}\text { Dip } \\
\text { (deg) }\end{array}$ & $\begin{array}{l}\text { Azimuth } \\
\text { (deg) }\end{array}$ \\
\hline E48 NPK8 & 41 & 8 & 290 & 20 & 11 & 022 & 12 & 76 & 165 \\
\hline E48 NPK9 & 39 & 10 & 102 & 24 & 10 & 010 & 18 & 76 & 237 \\
\hline
\end{tabular}

The measured in situ stress field consisted of nearly horizontal maximum and intermediate principal stresses and the minimum stress dipping at $76^{\circ}$. The stress vectors measured in ED4 are shown in a stereo plot in Figure 6, with the tunnel orientation indicated by a vector drawn along its axis. The minimum principal stress is oriented subvertically and because hydraulic fractures orient themselves to open against the minimum stress, the stress regime at E48 is conducive to growth of subhorizontal hydraulic fractures. This prediction is consistent with the hydraulic fracture orientations shown in Figure 6, as determined by analysis of the surface tilt measurements and as physically mapped after mining. The natural fracture orientations mapped along a $150 \mathrm{~m}$ long section of ED4 are also contained in Figure 6. Natural fractures were mapped with a range of orientations with higher concentration for subvertical fractures with a NE to EW strike.

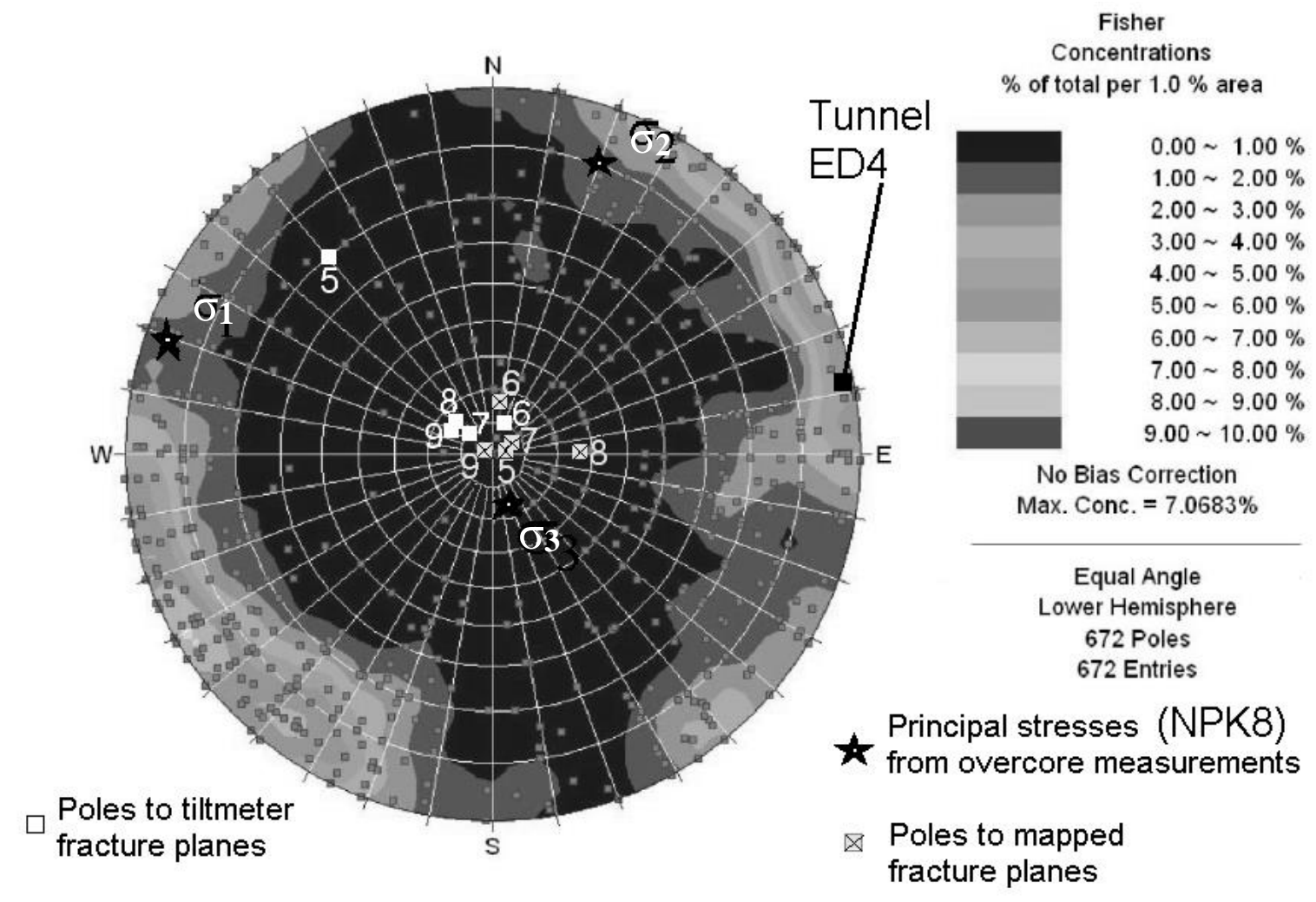

Figure 6 Natural fractures mapped along ED4 with measured principal stress vectors and poles to hydraulic fracture planes from tilt data and from physical mapping, each labelled with the corresponding hydraulic fracture number

\section{$6 \quad$ Results}

Over 300 microseismic events were detected during the hydraulic fracturing but did not cluster near the location of the hydraulic fractures. On the other hand, the tiltmeter monitoring provided a correct orientation for the hydraulic fractures within the expected accuracy of the method (Lecampion et al., 2005), with the exception of Fracture 5 which was mapped as subhorizontal, but (incorrectly) determined by the tilt analysis to be subvertical, with a poor fit between the data and forward model result. This fracture treatment had 
higher fluid loss than the other water treatments and, one possible explanation is that it intersected a conductive nearby fault that deformed and imparted a shear deformation signal to the tilt data. Tilt vectors (measured and best fit) for Fractures 5 and 6 are shown in Figure 7. The fit for Fracture 6 was good and the physically mapped fracture was found to agree with the orientation inferred from the tilt data analysis. The orientation determined for the physically mapped fractures was determined by fitting a plane through all of the mapped points. This method produces an average dip and dip direction. In the case of Fracture 8 , the average orientation obtained is strongly affected by the fact that a significant number of points lie along one major offset. Additional surveyed points on more exposure of the fracture would be needed to obtain a better average orientation for Fracture 8. Mapping and modelling of these hydraulic fractures is detailed in the next sections, followed by a discussion of the implications for preconditioning.


Figure 7 Measured (open arrowheads) and fitted (filled arrowheads) tilt vectors for a time near the end of the treatments for Fracture 5 (top) and Fracture 6 (bottom). The fit was poor for Fracture 5 and produced an orientation that did not match the physically mapped fracture 


\subsection{Physical mapping of hydraulic fractures}

Tunnel ED4 was driven through the zone containing the fractures, which were marked by coloured plastic proppant. The exposed fracture geometry was documented by photogrammetry, digital photography and mine surveying. Note that, for consistency with mine survey practice, distances are marked by the Chainage in Tunnel ED4. Adding $36.4 \mathrm{~m}$ to these figures gives the distance from the collar of the fracturing hole D102.

Figure 8 contains a grey scale photo showing a close up view of Fracture 8 (containing a green proppant) where it crossed a subvertical vein. The scale in the photo is marked in millimetres and centimetres. An offset in the fracture path was produced by the crossing interaction at this site. The distance in metres from the hole collar can be found by adding $36.4 \mathrm{~m}$ to the chainage metres shown in this and other figures.

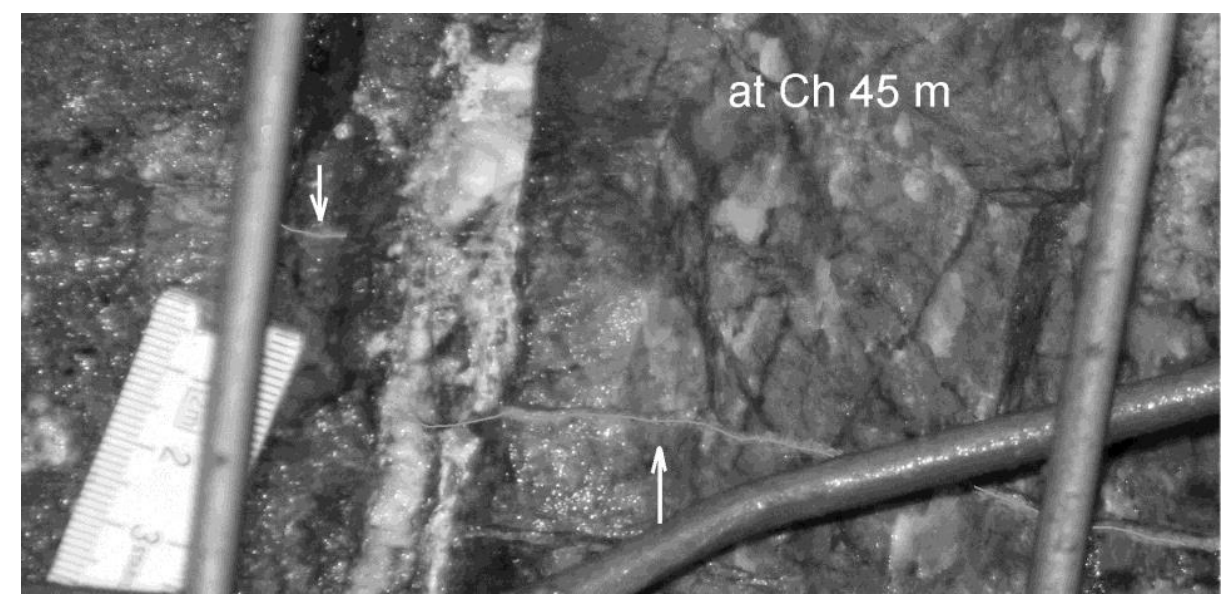

Figure 8 Hydraulic Fracture 8 is shown (propped with green plastic particles) at a location where it crossed a vein, producing an offset of about $20 \mathrm{~mm}$ in size. A thin light grey line has been drawn along the propped fracture to highlight its location

The physical mapping revealed the fractures to be subhorizontal and dipping west to southwest. The hydraulic fractures crossed shear zones, veins and natural fractures in their paths and developed offsets at locations where they crossed some of these features. Figure 8 contains a close up photograph, with the original colour photo converted to grey scale, of one of Fracture 8 (which was marked with green plastic proppant), crossing and offsetting at a quartz-calcite vein. The scale is marked in millimetres and centimetres. A composite view of the fracture geometry mapped along the tunnel is shown in Figure 9. Each fracture is shown in a different shade of grey, corresponding to the plastic proppant colour injected into it while it was being formed. The grey scale used in Figure 9 makes it difficult to separate the different fractures from one another, but the overall geometry is clearly shown. The physical mapping revealed the fractures to be subhorizontal and dipping west to southwest. 


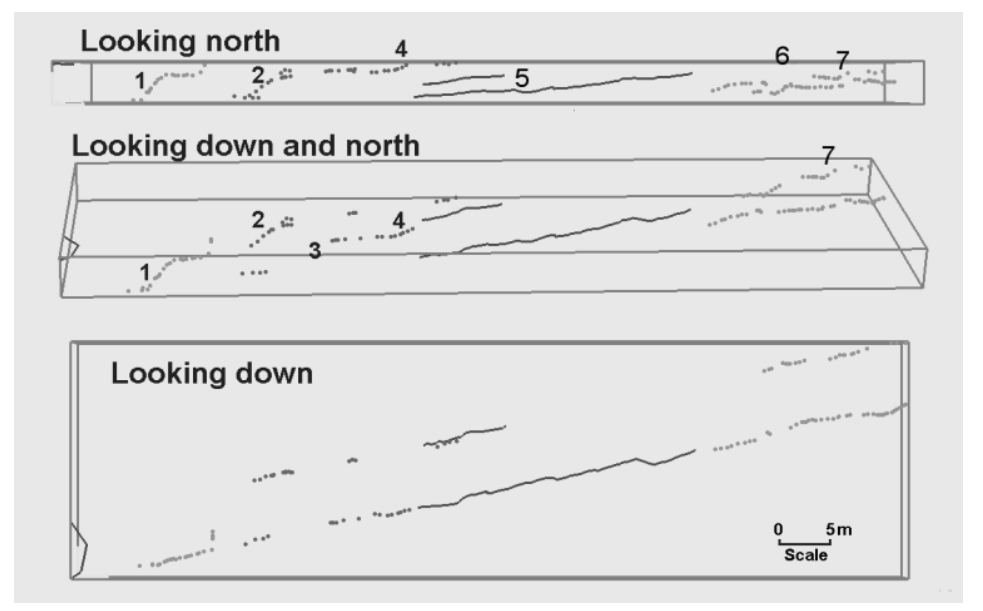

Figure 9 Elevation, oblique, and plan views of mapped fractures along the ED4 tunnel. Locations of seven large offsets are indicated by the numbers (after Jeffrey et al., 2009b)

One interesting observation is that fracture growth often results in a stair-stepping geometry in the mapped exposures. Figure 9 attests to hydraulic fractures that were generally oriented so that the opening direction was aligned with the least compressive stress (the vertical stress at this site). However, the hydraulic fractures would then be captured by a weak vein or natural fracture, growing along it for a few centimetres to a few metres, before escaping the natural feature, growing again in an orientation with the opening aligned with the least compressive stress. It will be shown in the modelling section that this characteristic stairstepping pattern can have profound effects on the fracture growth.

In spite of the stair-stepping geometry, the mapped fractures were generally found to grow more or less parallel with one another and, as expected, were oriented perpendicular to the minimum principal stress direction. Preconditioning costs are reduced if the boreholes, drilled for placement of the fractures, can be spaced more widely apart. A limit on borehole spacing is imposed by the distance to which fractures can be grown before they either diverge or converge. Determining this limit through experimentation and modelling is the subject of ongoing research.

\subsection{Modelling of fracture growth}

A 2D numerical hydraulic fracture model (Zhang et al., 2005) was used to study the effect of the offsets on fracture growth. A fracture path with offsets, as shown in Figure 10, was constructed. This predefined path was then opened by injecting fluid into the centre of the central horizontal segment, as indicated by the small circle in the centre. The steps are all aligned along the maximum compressive stress direction and the three offsets on each side of the injection point are placed at the angle of $90^{\circ}, 45^{\circ}$ and $40^{\circ}$ with respect to the maximum compressive stress direction, representative of offset orientations and sizes found during mapping. 




Figure 10 Offset fracture geometry, material parameters and in situ stresses used for numerical analyses

The initial closed fracture aperture is $0.01 \mathrm{~mm}$ along the whole fracture except for the two shortest offsets. The fracture aperture of two shortest $90^{\circ}$ offsets was varied and this aperture is denoted as $w_{01}$. The initial closed aperture provided fluid conductivity to the path and allows some fluid to penetrate through closed offset segments. The pressure associated with this fluid penetration helps to open the offset. Thus, the closed conductivity is an important parameter (Zhang and Jeffrey, 2008). Other parameters of the problem are shown in Figure 10.

The numerical results show that fractures with offsets grow much more slowly and require a higher pressure to extend compared to straight fractures (Jeffrey et al., 2009a). The detailed variations of the injection pressure and the fracture opening (width) at the borehole are displayed in Figure 11. More importantly, a narrow offset along a natural fracture, although it is very short, can result in a large pressure increase. Injecting more viscous fluid produces higher pressure. This finding affects the pump selection, injection rates and injection volumes required to create fractures of the desired size in a naturally fractured orebody.

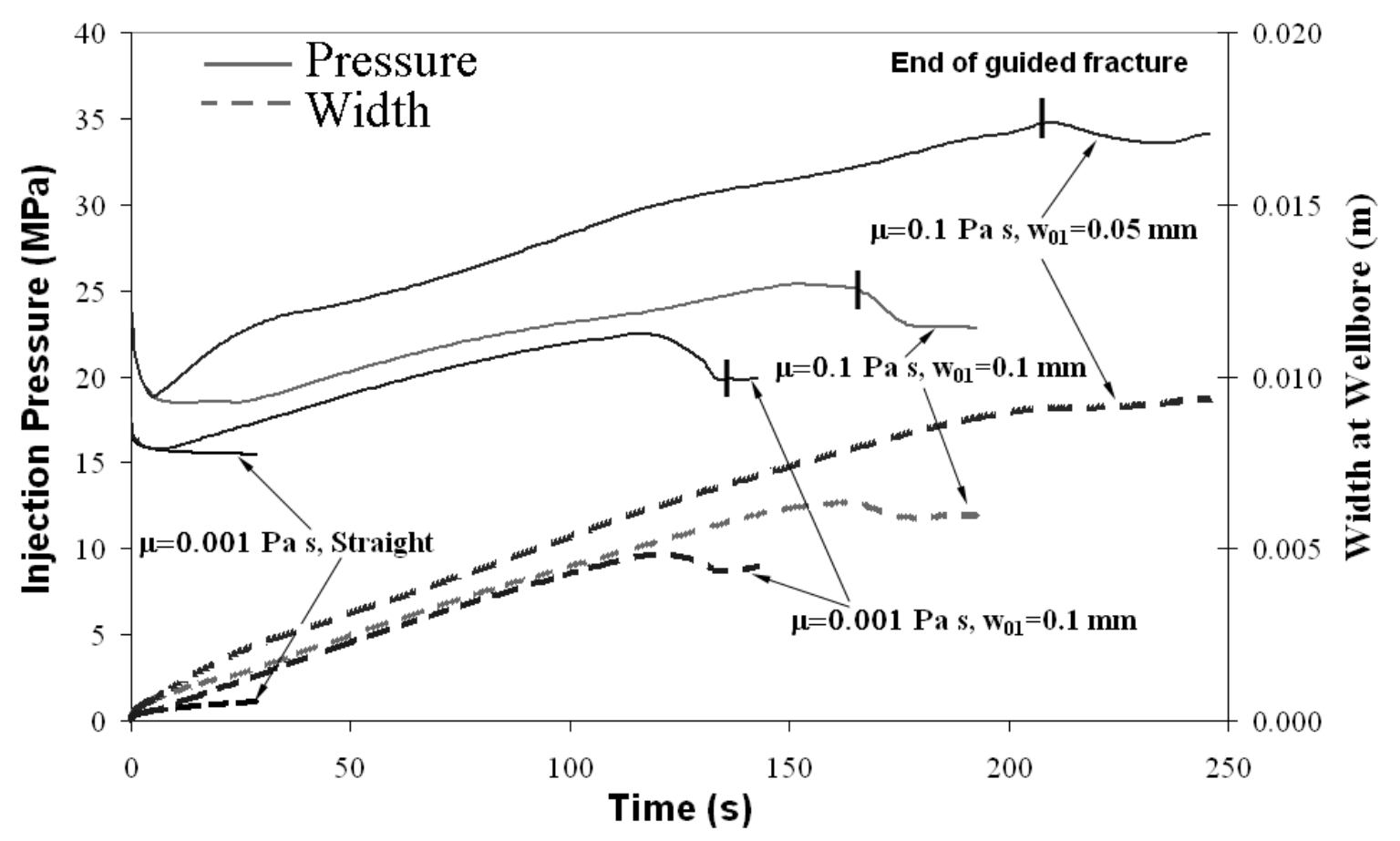

Figure 11 Pressure and opening responses at the borehole for different cases 
Figure 12 shows that gel-based fluids will produce wider fractures, and it is clear that the fracture opening along the offsets is increased for this case compared with the less viscous fluid. The field data supports these predictions in two ways. Firstly, the fractures that were formed using more viscous gel fluids did not suffer from the plastic proppant bridging across the fracture during injection, as evidenced by the lack of pressure increases associated with such events. Secondly, the plastic proppant was distributed over greater distances in the two hydraulic fractures that used gel-based fluids. However, we note that while hydraulic fractures extending more than $40 \mathrm{~m}$ were mapped during this project, their full extent was hidden as they grew into the tunnel floor and back (Jeffrey et al., 2009b).

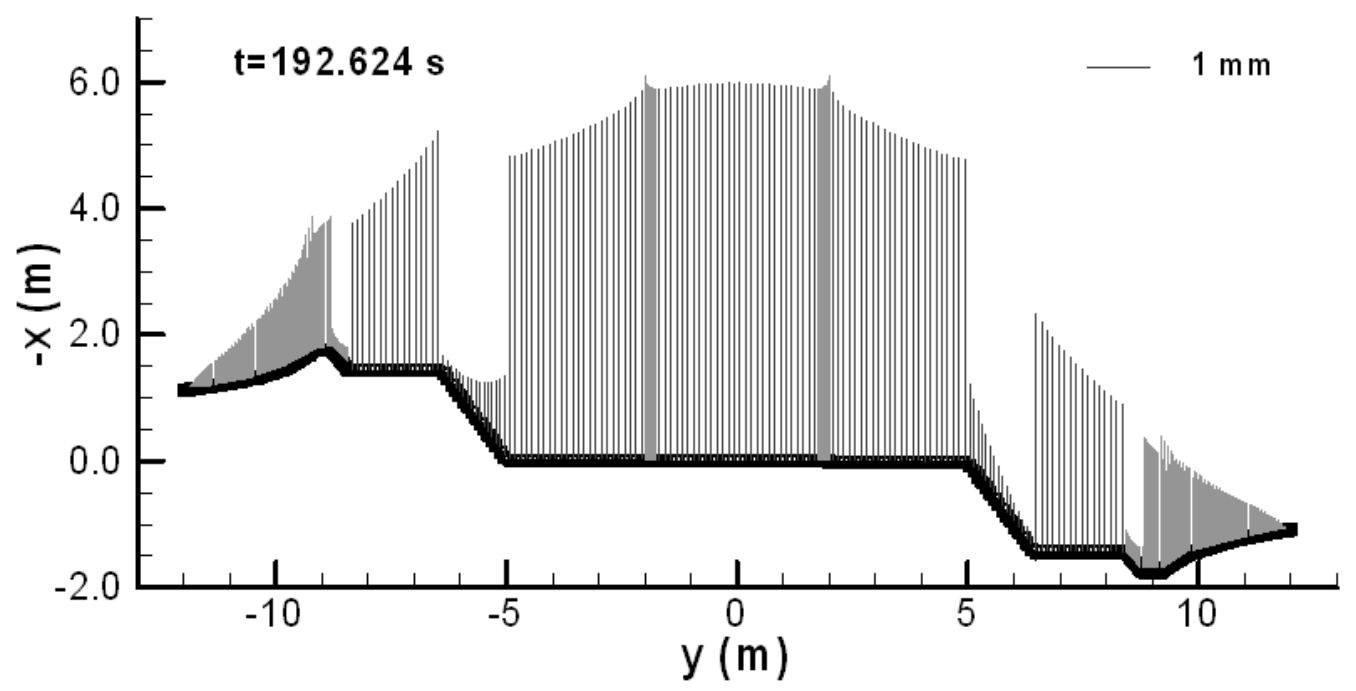

(a)

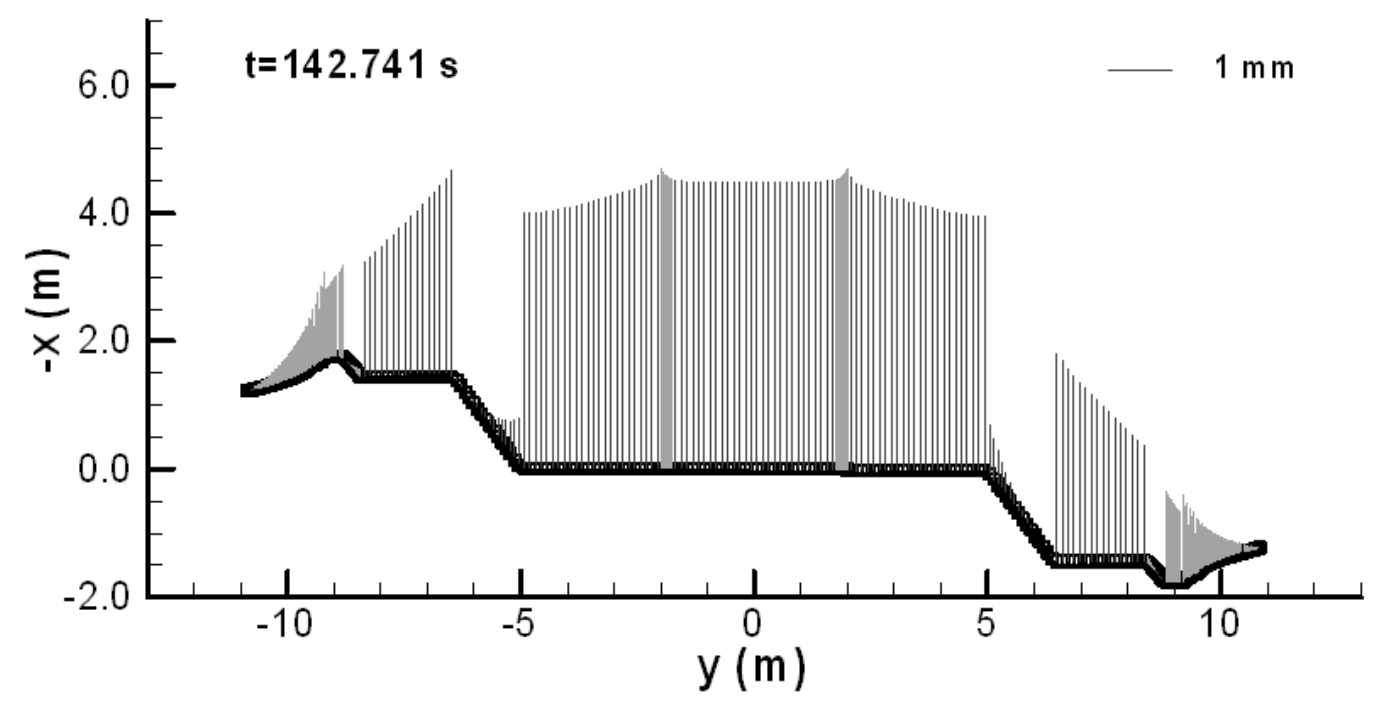

(b)

Figure 12 Opening profiles at a large time for two difference viscous fluids, (a) $\mu=0.1 \mathrm{~Pa}$ s; and (b) $\mu=0.001$ Pa $\mathrm{s}$

Subsequent seismic data analysis and modelling has been undertaken during the full scale preconditioning of the entire E48 deposit to evaluate the changes induced to the rock mass. The seismic analysis revealed the formation of a dominant structural orientation interpreted as the induced fracture network. The statistical analysis of the distributions of these seismic events revealed a dense network of structures with a spacing of around $2.5 \mathrm{~m}$, and estimated persistence of around 50-60 m. 


\subsection{Implications for preconditioning}

Three caveability assessments were conducted for the E48 deposit by independent consultants using different analysis methods. The first method was based on Laubscher's mining rock mass rating (MRMR) rock mass classification system and involved the use of Laubscher's Stability Chart (Laubscher, 1990). The second empirical method utilised the 'Extended Mathew's Stability Chart' based on the Mathews 'N' value (a derivative of the NGI Q system) (Trueman and Mawdesley, 2003). The third and final technique involved the use of numerical stress analyses (namely FLAC3D). All of these caveability analyses were extensive yet they were primarily based on drill core data with mapping data only becoming available towards the end of the feasibility study. The results from the empirical assessments indicated that caveability would be transitional though none could quantify the deleterious effects of the shear zones on caveability.

The numerical modelling analysis focused on the application of the new synthetic rock mass (SRM) methodology, developed from recent mass mining technology (MMT) research (Sainsbury et al., 2008). This methodology has been successfully tested through back-analysis of the E26, Lift 2 cave and is recognised as a significant improvement over previous caveability modelling. The methodology involves the construction of representative SRM samples for each geotechnical domain using the available rock mass data. The key differences between this approach and others are the explicit consideration of joint fabric and strength anisotropy, hence the models are well suited to include the effects induced through the introduction of discrete hydraulic fractures created during preconditioning.

Results from the SRM modelling indicated that the E48 caveability would prove problematic, with the potential for the cave to stall near surface at the upper contact between the VCCL and VSS units. This cave stall is attributed to the low horizontal stresses expected at this depth relative to the strength of the VSS. Subsequent modelling, that included the introduction of horizontal hydraulic fractures, showed that these on their own would not sufficiently weaken the rock mass to ensure continuous caving, although they did improve caveability. According to the SRM model, a cohesion reduction of around $40 \%$ is required for continuous caving conditions.

As a result of these studies, Northparkes have increased the E48 cave footprint in addition to the preconditioning the entire rock mass, the combination of both are expected to ensure continuous caving.

Although the SRM modelling conducted for the E48 caveability analysis, has the ability of simulating hydraulic fractures as existing horizontal structures, it did not simulate the process of hydraulic fracturing, the deleterious effects of which are well known and observed through monitoring.

As described in the preceding sections, the introduction of hydraulic fractures causes an increase in pore pressure in the surrounding rock mass, which cause both dilation and shear slip on natural fractures as a result of the reduction in the effective normal stress in the rock mass. Seismic monitoring at Northparkes has consistently revealed that often during fracturing (and for a period thereafter), the increase in microseismic activity is significant and some of which occurs quite remote from the fracture site. The effect of all these micro shear events in weakening the rock mass is certain, though difficult to quantify. Cross-hole seismic tomography in a preconditioned area revealed a reduction in the P-wave velocity by up to $4 \%$, which in this case equated to an approximate 15 percentage change in apparent fracture frequency. Subsequent analysis of induced seismic events, attributed to the preconditioning of the E48 deposit, have demonstrated that persistent, densely spaced fractures have been introduced into the rock mass though analyses of the seismic source parameters did not reveal significant damage to the rock mass in comparison to the influence of the undercutting process.

The induced stress changes measured in the region around the fracture zone are notable and extend considerable distances from the fracture. In one experiment at Northparkes, stress change was measured using ANZI cells (Mills, 1997) located between 40 and $80 \mathrm{~m}$ from the treatment zone and stress changes of between $0.5-1.0 \mathrm{MPa}$ were recorded after fracturing. During a preconditioning program, the treated rock mass will be subjected to numerous cycles of this fracture induced stress loading and unloading which may impart further damage to the rock mass.

Although the overall reduction in rock mass strength and consequent enhancement in caveability is difficult to quantify using conventional empirical methods or even numerical methods, for E48, a reduction in rock mass strength of at least $10 \%$ is required for successful caving. 


\section{Discussion}

The mine through data presented here and work done previously (van As and Jeffrey, 2002) has established that hydraulic fractures can be extended as essentially single fracture planes to sizes of $50 \mathrm{~m}$ in radius in naturally fractured rock by injection of water into short sections of boreholes isolated by packers. Furthermore, in the stress field and for the fracturing pressures experienced at Northparkes, the fractures tend to maintain their relative spacing over their mapped extent, despite following natural fractures and stepping along crosscutting fractures and shear zones. Measurement of seismic velocity changes by tomography have revealed significant changes in velocity are found when comparing pre- and post-fracturing data (van As et al., 2004). This indirect measurement of rock mass damage needs further study, perhaps by using borehole logging, by laboratory studies, and by core sampling and testing work before and after preconditioning. In addition, the amount and type of chemomechanical strength change should be studied. Changing the chemistry of the fracturing fluid to increase the overall weakening effect may prove to be a low-cost and effective improvement to preconditioning technology.

\section{Conclusions}

The tiltmeter monitoring provided, with one exception, accurate orientation data for the hydraulic fractures, which were placed $580 \mathrm{~m}$ below the array. Microseismic events were recorded coincident in time with the hydraulic fracturing treatments, but were not located around the points of fracture initiation. Events near the fractures may have been below the sensitivity threshold of the array or the events may have overwhelmed the limited bandwidth of the system.

The mapped fractures were subhorizontal, consistent with the measured in situ stress field. The hydraulic fractures grew through veins and natural fractures and some shear zones. A common feature of the fracture geometry was the presence of steps or offset in the fracture path. Offsets developed at locations where the hydraulic fractures grew into and along (usually oblique dipping) veins or shear zones. A 2D numerical hydraulic fracture model of such offset fracture growth shows that such fractures require higher pressure and grow more slowly than straight fractures.

The objective of any preconditioning program is ultimately to reduce the rock mass strength. For caving operations the design of a preconditioning program should not simply focus on improving the overall caveability and primary fragmentation but more importantly, it is to engineer greater homogeneity within the entire rock mass. For example, it would be far more desirable for a cave to propagate evenly over the entire footprint than for it to propagate rapidly in one area only. Preferential caving in one area of a cave often leads to early dilution and loss of reserves. Similarly, a more uniform fragmentation distribution is far easier to manage in terms of production draw scheduling and material handling than an orebody with sections of coarse or fine fragmentation. Thus, preconditioning has the potential to not only ensure caveability of finer fragmentation but if designed carefully, may also improve cave management and ultimately improve reserve recovery.

\section{Acknowledgements}

The authors thank CSIRO, Rio Tinto, and Northparkes Mines for permission to publish this paper and for supporting the work described. The monitoring and fracture mapping was supported by a consortium consisting of Northparkes, CSIRO, Shell E\&P, Schlumberger and Total E\&P. We thank these organisations for their support.

\section{References}

Brown, E.T. (2003) Block Caving Geomechanics, JKMRC Monograph Series in Mining and Mineral Processing 3, Julius Kruttschnitt Mineral Research Centre, The University of Queensland, Brisbane, 515 p.

Chacon, E., Barrera, V., Jeffrey, R.G. and van As, A. (2004) Hydraulic fracturing used to precondition ore and reduce fragment size for block caving, in Proceedings MassMin 2004 Symposium, Santiago.

Detournay, E. and Cheng, A.H-D. (1993) Fundamentals of Poroelasticity, Chapter 5 in Comprehensive Rock Engineering: Principles, Practice, and Projects, Vol. II, Analysis and Design Methods, C. Fairhurst (ed), Pergamon Press, pp. 113-171.

Jaeger, J.C. and Cook, N.G.W. (1976) Fundamentals of Rock Mechanics, John Wiley and Sons, New York, 585 p. 
Jeffrey, R.G., Zhang, X. and Thiercelin, M. (2009a) Hydraulic Fracture Offsetting in Naturally Fractured Reservoirs: Quantifying a Long-Recognised Process, Paper SPE 119351 presented at the SPE Hydraulic Fracturing Technology Conference, The Woodlands, Texas, 19-21 January.

Jeffrey, R.G., Bunger, A.P., Lecampion, B., Zhang, X., Chen, Z.R., van As, A., Allison, D.P., de Beer, W., Dudley, J.W., Siebrits, E., Thiercelin, M. and Mainguy, M. (2009b) Measuring Hydraulic Fracture Growth in Naturally Fractured Rock, Paper SPE 124919 presented at the SPE Annual Technical Conference and Exhibition, New Orleans, Louisiana, 4-7 October.

Laubscher, D.H. (1990) A geomechanics classification system for the rating of rock mass in mine design, Journal of South African Institute of Mining Metallurgy, Vol. 90(10), pp. 257-273.

Lecampion, B., Jeffrey, R. and Detournay, E. (2005) Resolving the geometry of hydraulic fractures from tilt measurements, Pure Applied Geophysics, Vol. 162, pp. 2433-2452.

Lhomme, T., Detournay, E. and Jeffrey, R.G. (2005) Effect of fluid compressibility and borehole on the initiation and propagation of a transverse hydraulic fracture, Strength, fracture and complexity, Vol. 3, No. 2-4.

Mills, K.W. (1997) In situ stress measurement using the ANZI stress cell, in Proceedings International Symposium on Rock Stress, pp. 149-152.

Mills, K.W. (2007) In Situ Stress Measurements - E48 Extraction Level, unpublished Report NPK3229, SCT Operations Pty Ltd.

Mills, K.W. and Jeffrey, R.G. (2004) Remote High Resolution Stress Change Monitoring near Hydraulic Fractures, in Proceeding MassMin 2004 Symposium, Santiago.

Ray, A.K., Singh, G.S.P. and Banerjee, G. (2006) Influence of petrographic constituents on the softening characteristics of Coal Measures rock, Technical Note, International Journal of Rock Mechanics and Mining Sciences, Vol. 43, pp. 494-502.

Sainsbury, B., Pierce, M.E. and Mas Ivars, D. (2008), Analysis of Cave Behaviour using a Synthetic Rock Mass (SRM) - Ubiquitous Joint Rock Mass (UJRM) Modelling Technique, in Proceedings First Southern Hemisphere International Rock Mechanics Symposium, SHIRMS, Perth, August 2008, Vol. 1, pp. 243-253.

Soliman, M.Y., East, L. and Adams, D. (2008) Geomechanics Aspects of Multiple Fracturing of Horizontal and Vertical Wells, SPE Drilling and Completion, September 2008, pp. 217-228.

Trueman, R. and Mawdesley, C. (2003) Predicting cave initiation and propagation, CIM Bulletin, Vol. 96(1071), pp. 54-59.

van As, A. (2004) Rock Strength Testing, unpublished Northparkes Mines report.

van As, A. and Jeffrey, R.G. (2000) Hydraulic fracturing as a cave inducement technique at Northparkes, in Proceedings MassMin 2000 Conference, pp. 165-172.

van As, A. and Jeffrey, R.G. (2002) Hydraulic fracture growth in naturally fractured rock: mine through mapping and analysis, in Proceedings North American Rock Mechanics Symposium - Tunnelling Association of Canada, Toronto, pp. 1461-1469.

van As, A., Jeffrey, R.G., Chacon, E. and Barerra, V. (2004) Preconditioning by hydraulic fracturing for block caving in a moderately stressed naturally fractured orebody, in Proceedings MassMin 2004 Symposium, Santiago.

Varley, F. and Whyatt, J. (2008) Work practices to manage bump prone ground, in Proceedings 27th International Conference on Ground Control in Mining, S.S. Peng, C. Mark, G.L. Finfinger, S.C. Tadolini, A.W. Khair, K.A. Heasley and Y. Luo (eds), Morgantown, West Virginia University, pp. 29-36.

Zhang, X., Jeffrey, R.G. and Detournay, E. (2005) Propagation of a fluid-driven fracture parallel to the free surface of an elastic half plane, International Journal for Numerical and Analytical Methods in Geomechanics, Vol. 29, pp. 1317-1340.

Zhang, X. and Jeffrey, R.G. (2008) Reinitiation or termination of fluid-driven fractures at frictional bedding interfaces, Journal of Geophysical Research, 113 B08416, DOI:10.1029/2007JB005327. 